EESTI NSV TEADUSTE AKADEEMIA TOIMETISED. 28. KOIDE GEOLOOGIA. 1979, NR. 4

ИЗВЕСТИЯ АКАДЕМИИ НАУК ЭСТОНСКОИ ССР. ТОМ 28

ГЕОЛОГИЯ. 1979, № 4

удК $551.732(474,2)$

Kaŭca MEHC

\title{
МИНЕРАЛОГИЧЕСКАЯ И ПАЛЕОНТОЛОГИЧЕСКАЯ ХАРАКТЕРИСТИКА СОЭЛАСКОЙ СВИТЫ
}

В разрезе нижнего кембрия Прибалтики глинистые породы, содержащие вверху вергальский и внизу люкатиский комплексы акритарх, разделены толщей крупнозернистых алевролитов и мелкозернистых песчаников, включающих лишь единичные тонкие прослои глинистых образований. Мощность этой песчано-алевритовой толщи на западе Эстонии колеблется от 28,4 (скв. Кингисепп) до 45 м (скв. Курису). Ее неоднородность впервые обнаружена при минералогическом изучении разрезов Балтийской синеклизы; было отмечено, что по минеральному составу и структурно-текстурным особенностям стратиграфическая эквивалентность внешне сходных тискреских (Эстония) и сакаских (Курземский полуостров) алевролитов вызывает серьезные сомнения (Менс, Пиррус, 1976). Дальнейшее изучение этой толщи, особенно ее минерального состава, на западе Эстонии показало, что ее нижняя половина соответствует тискреской свите стратотипической местности, а верхняя представляет собой базальную часть айсчяйской серии (Кала и др., 1979), которая названа соэлаской свитой (Решения ..., 1978).

Общая характеристика соэлаской свиты опубликована нами ранее (Кала и др., 1979). Ниже приводятся результаты минералогического и микропалеонтологического изучения соэласких отложений, а также некоторые новые данные об их строении, дополняющие характеристику соэлаской свиты и позволяющие уточнить ее положение в корреляционной схеме кембрия Прибалтики, пока еще условной (Решения .., 1978).

Соэлаские отложения имеют на западе Эстонии повсеместное распространение, залегая трансгрессивно на разновозрастных образованиях вплоть до пород кристаллического фундамента (рис. 1). Мощность свиты очень изменчива и колеблется обычно в пределах $18-30$ м. Минимальная мощность установлена в районе скв. Колувере-Румба-Казари, максимальная - в скв. Эммасте $(33$ м).

Нижняя граница свиты на юте Западной Эстонии характеризуется большой резкостью: рассматриваемые отложения с явным стратиграфическим несогласием залегают на размытой и нередко выветрелой поверхности подстилающих пород. Сложной становится проведение этой границы в пределах ареала распространения тискреских алевролитов, которые внешне мало отличаются от соэласких. Нередко в последнем случае эта граница проводится с большой условностью и главным образом по минералогическим данным. Соэлаские отложения перекрываются комплексом переслаивающихся алевролитов и глин ирбенской свиты, для которых характерны на островах отчетливо выраженная биотекстура типа «кракстен» и содержание в нижней части нескольких про1 ENSV TA Toimetised. G 41979 


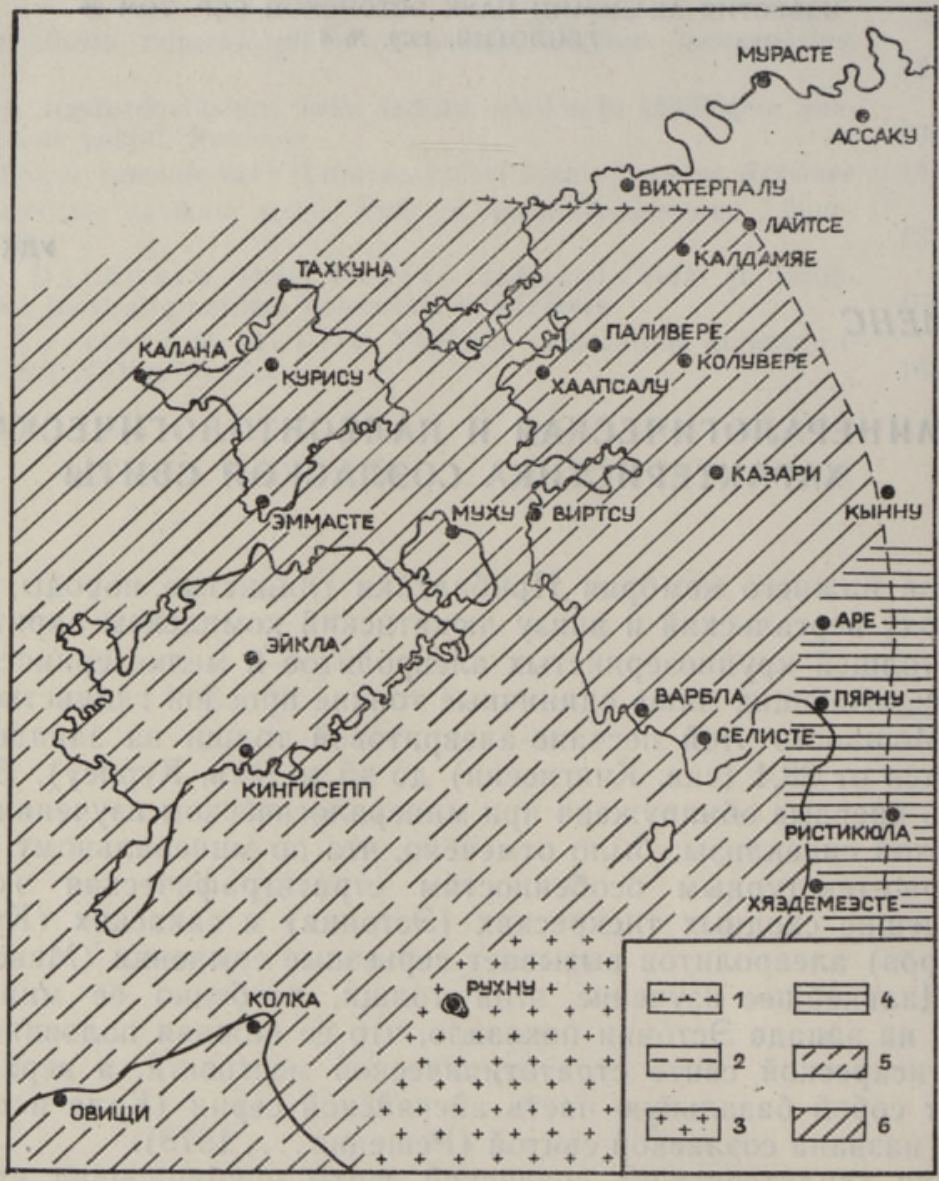

Рис. 1. Нижняя поверхность соэлаской свиты с расположением изученных буровых скважин. 1 - северная граница современного распространения отложений соэлаской свиты, 2 - предполагаемая восточная граница соэлаской свиты, 3 - кристаллический фундамент, 4 - балтийская серия, 5 - люкатиская свита, 6 - тискреская свита.

слоев, обогащенных бурыми гетитовыми оолитами. Проведение верхней границы затруднено в восточной прибортовой части синеклизы, где ввиду фациальных изменений вышеотмеченные критерии исчезают, ирбенская свита становится более однородной (алевритовой) и сливается с соэласкими отложениями в единую вакискую свиту.

Соэлаская свита сложена светлыми, почти белыми, крупнозернистыми алевролитами, содержащими нередко более $10 \%$ песчаных и гравийных зерен. В низах свиты имеется несколько прослоев пелитовых алевролитов, реже алевритовых глин. В средней и верхней частях свиты выдержанные прослои глинистых пород отсутствуют и здесь наблюдаются лишь тонкие пленки и отдельные гальки глин. Окраска пелитовых алевролитов зеленовато-серая, и только в некоторых разрезах (скв. Эммасте и Эйкла) наблюдаются фиолетово-серые или слабые фиолетово-красные пятна. Алевролиты свиты слабо сцементированы, чаще всего глинистым цементом, и только в нижней части нескольких разрезов встречается карбонатная цементация пойкилокластического типа в 
Рис. 2. Соотношение мине. ралов крупноалевритовой фракцин $(0,1-0,05$ м.м алевролитов тискреской $(\mathrm{E} t s)$, соэлаской $(\mathrm{E} s l)$ и ирбенской (Eir) свит 3aпадной Эстонии. $A$ - минеральный состав легкой фракции: 1 - кварц, 2 - полевые шпаты, 3 - слюды, 4 аутигенные минералы; 5 основные группы минералов тяжелой фракции: 1 черные рудные, 2 - прозрачные аллотигенные, 3 слюды, 4 - аутигенные минералы; $B$ - минеральный состав группы прозрачных аллотигенных тяжелых минералов: 1 - циркон, 2 турмалин, 3 - гранат, 4 Ті-минералы, 5 - остальные; $\Gamma$ - минеральный состав группы аутигенных тяжелых минералов: 1 - Tiминералы, 2 - пирит, 3 гидроокислы железа, 4 карбонаты.

виде сгустков. Текстура слоистая или массивная. Слоистость горизонтальная, участками наклонная и обусловлена чередованием крупнозернистых и пелитовых алевролитов или маркирована глинистыми пленками, реже присыпками слюд и глауконита. В низах свиты, особенно по
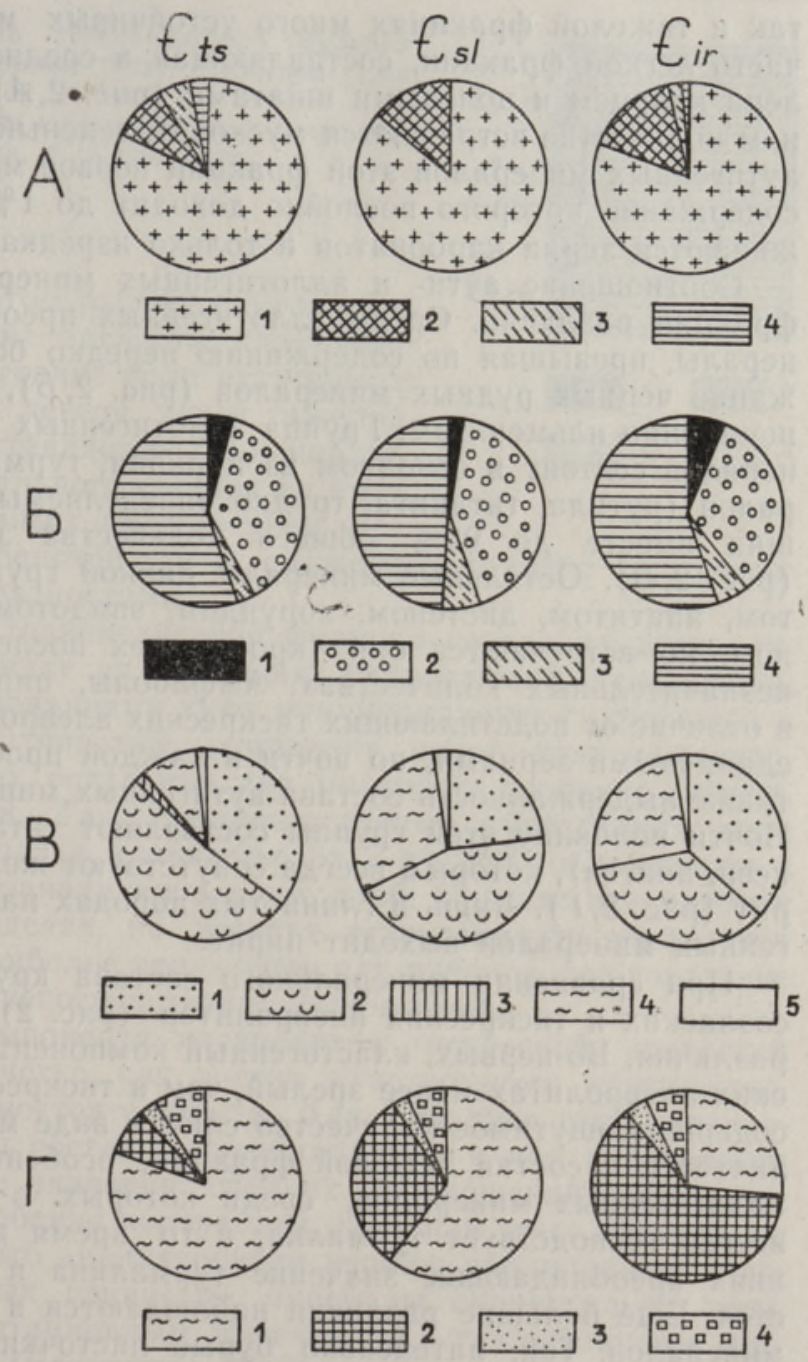

глинистым плоскостям, подчас обнаруживаются трещины усыхания, заполненные тем же алевритовым материалом, что и вмещающая порода.

Минералогические анализы выполнены по скв. Хаапсалу-3, Колувере, Румба, Варбла, Селисте, Пярну, Эммасте, Муху и Кингисепп (рис. 1). Поскольку преобладающими породами в соэлаской свите являются алевролиты, то характеристика минерального состава дается только по этому типу пород. Использованы данные 21 пробы из ирбенской, 22 проб из соэлаской и 7 проб из тискреской свит. Минеральный состав пород изучался иммерсионным методом по крупноалевритовой $(0,1$ 0,05 мм) и дифрактометрически по тонкопелитовой $(<0,001$ мм) фракциям. Крупноалевритовая фракция разделялась предварительно в бро-

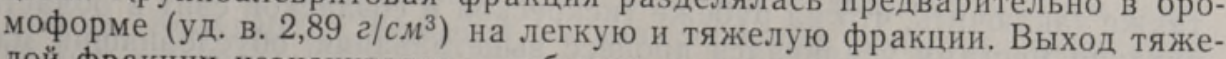
лой фракцин незначителен - обычно сотые доли процента, и лишь послойно наблюдаются более высокие значения (до $0,29 \%$ ), обусловленные концентрацией пирита, чаще всего вблизи глинистых прослоев.

В минеральном составе алевролитов соэлаской свиты как в легкой, 
так и тяжелой фракциях много устойчивых минералов. Аллотигенная часть легкой фракции, составляющая в среднем более $99 \%$, представлена кварцем и полевыми шпатами (рис.•2, $A$ ). Реже и в незначительном количестве встречаются мусковит, зеленый и бурый биотиты. Среди аутигенных минералов этой фракции первое место занимает глауконит, содержание которого послойно доходит до $1 \%$. Гораздо реже обнаруживаются зерна карбонатов и только изредка встречается каолинит.

Соотношение аути- и аллотигенных минералов в составе тяжелой фракции различно. Среди аллотигенных преобладают прозрачные минералы, превышая по содержанию нередко более чем в 10 раз содержание черных рудных минералов (рис. 2, Б), представленных преимущественно ильменитом. Группа аллотигенных прозрачных тяжелых минералов состоит в основном из циркона, турмалина и титановых минералов (рутила, титанита, трудно определяемых разностей), составляющих вместе до $98 \%$ общего количества минералов этой группы (рис. 2,B). Остальные минералы данной группы представлены гранатом, апатитом, дистеном, корундом, эпидотом, амфиболом и пироксеном, но встречаются они (кроме трех последних) спорадически и в незначительных количествах. Амфиболы, пироксены и эпидоты здесь в отличие от подстилающих тискреских алевролитов обнаружены хотя и единичными зернами, но почти в каждой пробе. Характерной является также выдержанность состава аутигенных минералов тяжелой фракции. Почти половину этой группы составляют титановые минералы (лейкоксен, анатаз), которым всегда сопутствуют железистые карбонаты и пирит (рис. $2, \Gamma$ ). Лишь в глинистых породах на первый план среди аутигенных минералов выходит пирит.

При сравнении минерального состава крупноалевритовой фракции соэласких и тискреских алевролитов (рис. 2) выясняются следующие различия. Во-первых, кластогенный компонент легкой фракции в соэласких алевролитах менее зрелый, чем в тнскреских, хотя в последних он содержит ощутимое количество слюд в виде мусковита. Во-вторых, различается и состав тяжелой фракции, особенно в группе прозрачных аллотигенных минералов, среди которых в тискреских алевролитах всегда господствует турмалин, в то время как в соэласких отложениях преобладающее значение турмалина и циркона послойно меняется. Еще бо́льшие различия наблюдаются в типоморфизме отдельных минералов. Так, интенсивно бурые листочки биотита (лепидомелан), синие турмалины и розовые цирконы более часты и характерны для алевролитов соэлаской свиты, а в подстилающих раннекембрийских породах разновидности этих минералов обнаруживаются в виде исключения. Среди минералов рассматриваемой группы в пробах соэлаской свиты еще много малаконизированных зерен циркона. В группе аутигенных тяжелых минералов соэласких алевролитов всегда встречаются круглые стяжения (глобулы) железистого карбоната и скопления агрегатного анатаза, а в тискреских отложениях первые вообще не обнаружены.

Все это однозначно указывает на появление в начале соэлаского осадконакопления дополнительного источника сноса, сложенного породами, содержащими синие турмалины, розовые цирконы и лепидомелан. На основе минерального состава кластогенного компонента можно также заключить, что на рубеже тискреской и соэлаской свит в области питания местами усиливался процесс выветривания, обусловивший малаконизацию циркона и превращение первичных титановых минералов (рутил?) в анатаз.

Переход к вышележащим отложениям ирбенской свиты минералоги- 
Рис. 3. Минеральный состав тонкопелитовой фракции $<0,001$ мм) алевролитов тискреской $(\mathrm{E} t s)$, соэлаской $(\mathrm{E} s l)$ и ирбенской (Eir) свит Западной Эстонии. 1 - хлорит, $2-$ смешаннослойный минерал типа монтмориллонит-гидрослюда, 3 - гидрослюда, 4 - каолинит.

чески менее четкий. На этом рубеже отмечаются еще некоторое уменьшение зрелости кластогенного компонента и возрастание роли аутигенных минералов в спектре как легкой, так и тяжелой фракций (рис. 2). Представляется, что наблю-

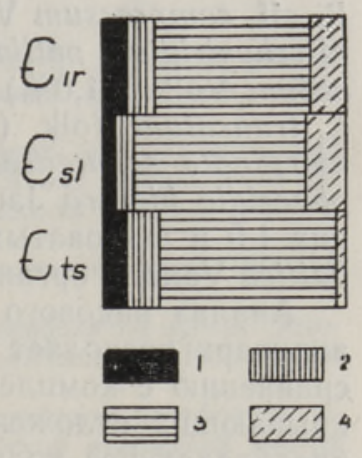
даемые изменения минерального состава на этом уровне скорее всего связаны с уменьшением зернистости алевролитов ирбенской свиты, сложенных нередко пелитистыми и даже пелитовыми разностями.

Глинистые минералы тонкопелитовой фракции соэласких алевролитов представлены (в порядке их убывания) гидрослюдой, каолинитом, смешаннослойными образованиями типа монтмориллонит-гидрослюда и хлоритом. Чаще всего глинистый компонент имеет гидрослюдистокаолинитовую ассоциацию, остальные два минерала, ссобенно хлорит, встречаются спорадически. Так, смешаннослойные образования типа монтмориллонит-гидрослюда в количестве от 5 до $25 \%$ обнаружены в большей части $(60 \%)$ проанализированных проб. Содержание хлорита колеблется в тех же пределах, но частота встречаемости составляет $40 \%$, и его присутствие наиболее характерно для районов, где соэлаские отложения подстилаются непосредственно тискрескими.

Состав глинистого компонента алевролитов тискреской, соэлаской и ирбенской свит не так четко, как состав кластогенного компонента, свидетельствует об их самостоятельности. Для всех трех свит характерен четырехкомпонентный состав с преобладанием в нем гидрослюды (рис. 3). Количественные значения средних соотношений отдельных компонентов также не особенно контрастны. Причина этого кроется, по всей вероятности, в том, что анализировали хорошо проницаемые алевритовые породы, в которых глинистые минералы сравнительно легко подвергались постседиментационным изменениям, сглаживающим первоначальные их различия (Брангулис, 1977).

Таким образом, судя по минеральному составу крупноалевритовой и тонкопелитовой фракций алевролитов, соэлаские отложения генетически стоят ближе к покрывающим ирбенским, чем к подстилающим тискреским, отличаясь от последних не только набором и количеством минеральных компонентов, но нередко и типоморфизмом отдельных минералов.

Органические остатки в породах соэлаской свиты немногочисленны. $\mathrm{K}$ настоящему времени обнаружены лишь мелкие фрагменты раковин беззамковых брахиопод. Так же незначительно количество ихнитов, которые приурочены в основном к глинистым поверхностям наслоения и представлены обычно формами Skolithos диаметром $1-3$ мм. Только в скв. Колувере найдены единичные экземпляры диаметром до 8 м.. Еще реже обнаружены ихниты типа Planolites - диаметр $1-3$ мм (скв. Тахкуна, Колувере). Несмотря на многократные попытки, акритархи удалось получить только из скв. Варбла (глубина 440,1 м), где в зеленовато-серых алевритовых глинах Н. А. Волковой обнаружен следующий их набор: Baltisphaeridium dubium Volk. $(13,0 \%)$, B. implicatum Fridr. $(1,0 \%)$, B. ciliosum Volk. $(1,0 \%)$, B. strigosum Volk. $(0,5 \%)$, 
B. aff. compressum Volk. $(0,5 \%)$, B. varium Volk. $(0,5 \%)$, B. sp. $(0,5 \%)$, Micrhystridium pallidium Volk. $(4,0 \%)$, M. lanatum Volk. $(1,0 \%), M$. tornatum Volk. (1,0\%), Lophosphaeridium aff. tentativum Volk. $(1,5 \%)$, L. truncatum Volk. (0,5\%), Tasmanites bobrowskii Waz. $(5,0 \%)$, Granomarginata squamacea Volk. $(0,5 \%)$, Cymatioshaera sp. $(1,5 \%)$, Leiosphaeridia bicrura Jank. $(3,0 \%)$, L. sp. sp. $(63,0 \%)$, Ooidium sp. (гладких 1,0 и шиповатых $1,0 \%)$. Кроме названных, много также Aliumella baltica Vand. и органических нитей.

Анализ видового состава обнаруженных в соэласких отложениях акритарх позволяет отметить определенное своеобразие их набора по сравнению с комплексами этих окаменелостей из подстилающих и покрывающих отложений. Характерным для этого сообщества является преобладающее количество лейосферидий, в то время как количество и разнообразие акантоморфных форм невелико. Это, по-видимому, обусловлено гидродинамически активными мелководными условиями осадконакопления в соэлаское время. На это указывает также сравнительно большое количество оболочек Tasmanites и оойдных форм среди акритарх, а также характер ихнитов. Необычной, не отмеченной ранее в других комплексах, является здесь ассоциация акритарх, представленная типичными люкатискими формами (Baltisphaeridium dubium, Micrhystridium pallidium и Lophosphaeridium tentativum), с одной стороны, и более поздними (Baltisphaeridium ciliosum, B. strigosum, B. varium, Micrhystridium lanatum и Lophosphaeridium truncatum) с другой. Появление последних в отложениях раннего кембрия на Восточно-Европейской платформе известно лишь с подошвы вергальского горизонта (Волкова, 1973; Фридрихсоне, 1974). В то же время среди соэласких акритарх не обнаружено специфического для вергальского комплекса вида Estiastra minima Volk.

Близкий к описанному комплекс обнаружен В. В. Кирьяновым (1979) в верхней части любомльской свиты в скв. Корытница на Волыни. В отличие от соэлаского сообщества здесь найдены единичные экземпляры B. cerinum Volk. и Estiastra minima Volk.

В заключение следует остановиться на дискуссионном до настоящего времени вопросе - о соответствии соэлаской свиты и ее стратиграфических аналогов талсинскому (Брангулис и др., 1976) или вергальскому горизонту (Решения..., 1978). Сравнительно небольшая палеонтологическая информация о соэласких отложениях не позволяет сделать какие-либо окончательные биостратиграфические выводы. Но имеющийся материал вместе с данными о структурном плане соэласких отложений и их минеральном составе показывает, что породы соэлаской свиты теснее связаны с отложениями вергальского, чем талсинского горизонта. Между тем не исключено, что набор акритарх из отложений соэлаской свиты представляет собой независимый комплекс, характеризующий в корреляционной стратиграфической схеме кембрия Восточно-Европейской платформы самостоятельное подразделение, соответствующее, по-видимому, горизонту.

Из сказанного следует, что постталсинский возраст отложений соэлаской свиты очевиден, но отнесение их к вергальскому горизонту может быть только условным. Для решения вопроса их погоризонтной принадлежности необходимы дальнейшие поиски и изучение как фауны, так и акритарх. 


\section{Л И ТЕ Р А Т Р А}

•Брангулис А. П., Мурниекс А. Э., Фридрихсоне А. И. Кембрийская система, - В кн.: Стратиграфические схемы Латвийской ССР. Рига, 1976, c. $23-25$.

Брангулис А. П. Влияние постседиментационных изменений на коллекторские свойства кембрийских терригенных пород Латвии. - В кн.: Литология и полезные ископаемые палеозойских отложений Прибалтики. Рига, 1977, с. $44-50$.

В олков а Н. А. Акритархи и корреляция венда и кембрия западной части Русской платформы. - Сов. геол., 1973, № 4, с. 48-62.

К ал а Э. А., Мен с К. А., П и р у с Э. А. К стратиграфии кембрия на западе Эстонии. - В кн.: Стратиграфия древнепалеозойских отложений Прибалтики. Таллин, 1979.

К и р ь н о в В. В. Волыно-Подольский склон Восточно-Европейской платформы. В кн.: Стратиграфия верхнедокембрийских и кембрийских отложений запада Восточно-Европейской платформы. М., 1979.

Менс К. А., Пи р р у с Э. А. О литолого-минералогических критериях расчленения терригенных отложений венда и кембрия Прибалтики. - В кн.: Материалы по стратиграфии Прибалтики. Внльнюс, 1976, с. $27-28$.

Решения Межведомственного регионального стратиграфического совещания по разработке унифицированных стратиграфических схем Прибалтики, 1976 г. Л., 1978.

Ф и дрихсоне А. И. Уточнение подразделения кембрийской системы в Латвии. В кн.: Региональная геология Прибалтики. Рига, 1974, с. 3-15.
Институт геологии
Академии наук Эстонской ССР
Поступила в редакцию
27/III 1979

Kaisa MENS

\section{SOELA KIHISTU MINERALOOGILINE JA PALEONTOLOOGILINE ISELOOMUSTUS}

On esitatud uusi, peamiselt mineraloogilise ja mikropaleontoloogilise (akritarhid) analüüsi tulemustele tuginevaid andmeid soela kihistu kohta. Kihistu täpne asend regionaalses stratigraafilises skeemis ei ole paleontoloogilise materjali vähesuse tōttu praegu veel kindel. Saadud tulemuste põhjal vōib väita, et soela kihistu terrigeensete setete kuhjumisega algas basseini arengus uus, aisčiai etapp.

\section{Kaisa MENS}

\section{MINERALOGICAL AND PALAEONTOLOGICAL CHARACTERISTICS OF THE SOELA FORMATION}

The Soela Formation has been recently distinguished in the Early Cambrian sequence of Estonia. Its deposits transgressively overlie different-aged (Tiskre, Lükati, Lontova, or the crystalline basement) rocks (Fig. 1) that have frequently been weathered. The formation is mainly represented by light-coloured, coarse-grained siltstones with small intercalations of clayey rocks in the lower part. Its thickness varies from 14 to $33 \mathrm{~m}$.

Mineralogical composition of siltstones was studied by immersion in silt $(0.1-$ $0.05 \mathrm{~mm})$ and X-ray diffraction in clay $(<1 \mu)$ fractions. The results of the study of the silt fractions and their comparison with the ones obtained from the underlying Tiskre $\left(E_{1} t s\right)$ and overlying Irbeni ( $E_{1}$ ir) formations are given in Fig. 2. In this figure the content of light minerals $(A)$, that of heavy minerals $(B)$, numerical relations in the group of transparent allothigenous heavy minerals $(B)$ and those in the group of authigenous heavy minerals $(\Gamma)$ are shown, Clay minerals in siltstones are frequently 
represented by illite (3), kaolinite (4), mixed-layered montmorillonite-illite (2) and chlorite (1) (Fig. 3). The mineral composition of the clayey fraction varies very little throughout the Tiskre, Soela and Irbeni Formations, evidently due to the post-sediment? al processes unifying the composition of permeable coarse-grained siltstones.

The Soela Formation is rather poor in fossils. Of fauna, it contains only rare indeterminable fragments of brachiopods and some trace fossils, mostly of the genus Skolithos. Acritarchs have so far been established only in the Varbla borehole $(440.1 \mathrm{~m})$. Among them, the species of the genus Leiosphaeridia are most abundant, whereas the species of Baltisphaeridium and Micrhystridium are much more limited. The acritarch assemblage is of transitional character between the Lükati and Vergale ones, consisting of some typical former elements (Baltisphaeridium dubium, Micrhystridium pallidium and Lophosphaeridium tentantivum) together with B. ciliosum, B. strigosum, B. varium, $M$. lanatum and L. truncatum, which are known to begin with the bottom of the Vergale Stage, while the species of the typical later genus - Estiastra - has not been found.

On the grounds of the presented data, the Soela Formation initiates the third Early Cambrian sedimentary cycle in the studied area, belonging to the Aisčiai Series. The question whether the Soela Formation forms an independent stage on the regional scale of the East-Baltic Cambrian, or whether it corresponds to the Vergale Stage, requires further investigation. 